\title{
Natural frequencies of a flat viaduct road part simply supported on two ends
}

\author{
ISMAIL YÜKSEK ${ }^{1}$, AHMET ÇELIK ${ }^{1}$ and KAYHAN GÜLEZ ${ }^{2}$ \\ ${ }^{1}$ Yildiz Technical University, Mechanical Engineering Faculty, Mechanical \\ Engineering Department, 34349, Beşiktaş, İstanbul, Turkey \\ ${ }^{2}$ Yildiz Technical University, Electrical-Electronics Faculty, Electrical \\ Engineering Department, 34349, Beşiktaş, İstanbul, Turkey \\ e-mail: gulez@yildiz.edu.tr
}

MS received 7 December 2004; revised 29 March 2005

\begin{abstract}
Viaduct roads have wide application in big cities with high traffic loads, in order to decrease traffic density and to connect subways to highways. Viaduct roads are constructed using steel structures instead of concrete ones in areas of earthquake risks. The low weight of steel structures however causes problems such as vibration and noise. There is increasing demand especially in populated areas to suppress vibration and noise on highway roads for reducing noise-related environmental pollution.

In this study, bending vibrations of rectangular plate viaduct roads, which are supported by six fixed elements of rectangular cross-sectional elements are considered. Natural frequencies are obtained using the Rayleigh-Ritz technique, finite elements analysis, experimentally and neural networks (NN).
\end{abstract}

Keywords. Bending vibration; natural frequency; rectangular plate; RayleighRitz technique; neural networks.

\section{Introduction}

Stiffened plates are important structural elements that are used commonly in airplanes, ships, railway vehicles, floor systems and bridges. Vehicles passing on these plates create vibrations, as do earthquakes. If the natural frequency of these forces coincides with the natural frequency of the system, resonance occurs and thus causes the failure of the system (bridge, building etc.). For this reason, determinations of the natural frequencies are very important (Long 1971; Ney \& Kulkarni 1972; Srinivasan \& Munaswamy 1978; Balendra \& Shanmugan 1982; Bhat 1982; Bert \& Newberry 1986; Heyliger \& Reddy 1988; Mukherjee \& Mukhopadhyay 1988; Mukhopadhyay 1989).

Many researchers have tested the dynamic behaviour of structural elements such as beams and plates. Analyses on these systems were conducted on the basis of some methods such

A list of symbols is given at the end of the paper. 
as those by Leissa $(1969,1973)$, Basilly \& Dickinson (1975), Kim \& Dickinson (1987), Sakata \& Hosokawa (1988) and Kim et al (1990). These methods are suitable approaches for the solution of the system with appropriate mathematical models. Leissa (1973) tested the free lateral vibrations of thin rectangular plates and also used series type functions approaches for beams and plates. In free edge plate problems, some degenerated beam functions were proposed by Basilly \& Dickinson (1975) for the condition for which the Rayleigh-Ritz method was applied. Kim \& Dickinson (1987) examined the bending vibrations of linearly supported plate systems with Rayleigh-Ritz method. Sakata \& Hosokawa (1988) used even trigonometric series and found more accurate results for natural frequencies of rectangular cantilevered skew plates. Kim et al (1990) tested the lateral vibrations of rectangular plates by using simple polynomials in the Rayleigh-Ritz method.

During the preliminary design stage of natural frequency, the designers should have reliable and preferably practical design tools for defining these kinds of parameters of the viaducts. As an inevitable alternative, Neural Networks (NN) have been increasingly utilized in many disciplines such as control, early detection of machine faults, robotics, mechatronic systems etc. as well as design and dynamic system problems. The usefulness of NN process is the capability of solving nonlinear problems in which the convergence cannot be provided using linear approaches. Thus, the identification of high precision nonlinear relations becomes easier with the benefit of the efficient algorithms presented by Neural Networks (NN).

In this study, natural frequency values of a viaduct road model that is simply supported at two ends are determined with Rayleigh-Ritz method. Comparing the experimental values found by Rayleigh-Ritz method is used for the basis of neural networks in training phase. Thus, after the $\mathrm{NN}$ model is trained once, other required frequency values are easily determined in the test phase of the algorithm.

\section{Mathematical formulation}

Viaduct roads are generally constructed by connecting straight and inclined plates. A schematic of the straight part of a viaduct road model is given in figure 1 , composed of one plate with dimensions of $1.8 \times 0.9 \times 0.006 \mathrm{~m}$ and 6 beams with dimensions of $1.8 \times 0.2 \times 0.004 \mathrm{~m}$ supporting the plate at the bottom (Yuksek et al 2000). This model is constructed with the example of viaduct road structures mostly used in Tokyo. In the experimental work part, a real viaduct road model is given.

\subsection{Rayleigh-Ritz method}

Solutions of differential equations are known for simply supported rectangular plates (Leissa 1969) whose one side is a cantilever and other sides have different connection properties. For

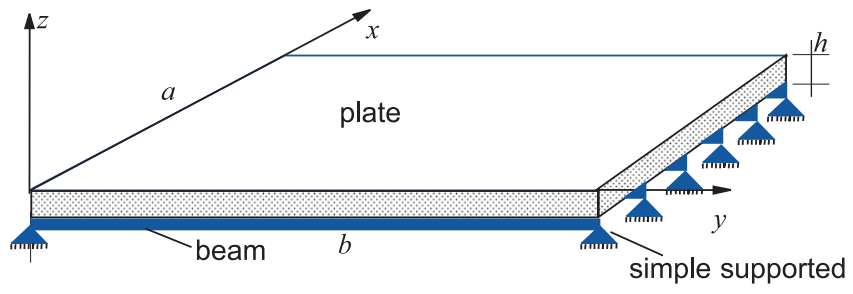

Figure 1. Flat viaduct road model. 
the solutions of plates that have various boundary conditions, numerical methods must be taken into account. For such problems, the method by Ritz (Young 1950) was very useful. For the stiffened plates that are composed of beams and plates together, approximate solutions for equations can be determined by Rayleigh-Ritz method.

In this study, the Rayleigh-Ritz method used in the vibrational analysis of stiffened rectangular plate, beam functions are used for displacement function (Szilard 1974). We will deal with a rectangular plate problem, simply supported along the short face-to-face sides a, free along long sides $b$, and with 6 beams of rectangular cross-section supporting the rectangular plate. The potential energy expression, for a rectangular plate that is supported by 6 prismatic beams parallel from bottom part to side $b$, is;

$$
\begin{aligned}
V= & \int_{0}^{a} \int_{0}^{b} \frac{1}{2} D\left[\left(\frac{\partial^{2} w}{\partial x^{2}}\right)^{2}+\left(\frac{\partial^{2} w}{\partial y^{2}}\right)^{2}+2 v \frac{\partial^{2} w}{\partial x^{2}} \frac{\partial^{2} w}{\partial y^{2}}\right. \\
& \left.+2(1-v)\left(\frac{\partial^{2} w}{\partial x \partial y}\right)^{2}\right] \mathrm{d} x \mathrm{~d} y \\
& +\frac{1}{2} \sum_{k=1}^{6}\left[E_{k} I_{k} \int_{0}^{b}\left(\frac{\partial^{2} w}{\partial y^{2}}\right)_{x_{k}}^{2} \mathrm{~d} y+G_{k} J_{k} \int_{o}^{b}\left(\frac{\left.\partial^{2} w\right)}{\partial x \partial y}\right)_{x_{k}}^{2} \mathrm{~d} y\right] .
\end{aligned}
$$

And kinetic energy expression is;

$$
\begin{aligned}
T & =\frac{1}{2} \rho h \int_{0}^{a} \int_{0}^{b}\left(\frac{\partial w}{\partial t}\right)^{2} \mathrm{~d} x \mathrm{~d} y+\frac{1}{2} \sum_{k=1}^{6}\left[\rho_{k} A_{k} \int_{0}^{b}\left(\frac{\partial w}{\partial t}\right)_{x_{k}}^{2} \mathrm{~d} y\right] \\
D & =\frac{E h^{3}}{12\left(1-v^{2}\right)} .
\end{aligned}
$$

Here, $D$ is plate rigidity, $I_{k}$ beam rigidity, $\rho_{k}$ beam density, $A_{k}$ lateral cross-section of beam Due to assumptions that vibrations are harmonic, the expression for small oscillations of the stiffened rectangular plate's middle surface, can be written as,

$$
w=W(x, y) e^{i \omega_{n} t} .
$$

In the expressions of potential and kinetic energy, substituting the necessary derivatives of $w$, for maximum energy expressions we find that

$$
\begin{aligned}
V_{\max }= & \frac{1}{2} D \int_{0}^{a} \int_{0}^{b}\left[\left(\frac{\partial^{2} W}{\partial x^{2}}\right)^{2}+\left(\frac{\partial^{2} W}{\partial y^{2}}\right)^{2}+2 v \frac{\partial^{2} W}{\partial x^{2}} \frac{\partial^{2} W}{\partial y^{2}}\right. \\
& \left.+2(1-v)\left(\frac{\partial^{2} W}{\partial x \partial y}\right)^{2}\right] \mathrm{d} x \mathrm{~d} y \\
& \times \frac{1}{2} \sum_{k=1}^{6}\left[E_{k} I_{k} \int_{0}^{b}\left(\frac{\partial^{2} W}{\partial y^{2}}\right)_{x_{k}}^{2} \mathrm{~d} y+G_{k} J_{k} \int_{0}^{b}\left(\frac{\partial W^{2}}{\partial x \partial y}\right)_{x_{k}}^{2} \mathrm{~d} y\right], \\
T_{\max }= & \frac{1}{2} \rho h \omega_{n}^{2} \int_{0}^{a} \int_{0}^{b} W^{2} \mathrm{~d} x \mathrm{~d} y+\frac{1}{2} \omega_{n}^{2}\left[\sum_{k=1}^{6} \rho_{k} A_{k} \int_{0}^{b}(W)_{x_{k}}^{2} \mathrm{~d} y\right] .
\end{aligned}
$$


Displacement function in energy expressions is assumed as,

$$
W(x, y)=\sum_{m} \sum_{n} a_{m n} \phi_{m}(x) \sin \frac{n \pi y}{b}, \quad m=1,2,3, \ldots 8, \quad n=1,2,3, \ldots 8,
$$

and only first eight terms are considered.

Here,

$$
\begin{aligned}
& m=1, \text { then } \phi_{1}=1 ; m=2 \text {, then } \phi_{2}=2\left(\frac{x}{a}\right)-1 \text {; } \\
& m>2, \text { then } \phi_{m}(x)=\cosh \left(\lambda_{m} x / a\right)+\cos \left(\lambda_{m} x / a\right) \\
& -\frac{\cosh \lambda_{m}-\cos \lambda_{m}}{\sinh \lambda_{m}-\sin \lambda_{m}}\left[\sinh \left(\lambda_{m} x / a\right)+\sin \left(\lambda_{m} x / a\right)\right], \\
& \lambda_{m}=(2 m-3) \pi / 2, \quad m=3,4,5, \ldots .
\end{aligned}
$$

Using the energy expressions in Rayleigh-Ritz method and minimizing the Rayleigh ratio according to unknown coefficients $a_{i}$, in a way,

$$
\left(\partial / \partial a_{i}\right)\left(V_{\max }-T_{\max }\right)=0 .
$$

Basic value expression is determined. In the solution of (9) the following matrix form is used and natural frequencies of basic value problem are determined.

$$
\sum\left[A_{i j}-\omega_{n}^{2} B_{i j}\right] a_{i j}=0
$$

\section{Experimental settings}

A real viaduct road model is seen in figure 2 . The setting of this model and the sensor and magnetic force actuator are given in figures 3 and 4 respectively.

The experiment set up performs modal analysis of viaduct road model's straight part. By means of this analysis, it becomes possible to test the natural frequency values, mode shapes and damping effects.

Experiment is conducted in two different ways. In the first case, impulse hammer is used, in the second case, by placing a magnetic damper under the road as seen in figures 3 and 4 . The exit of signal generator is connected to a power amplifier. In both systems a sensor is placed on the road. The exit of sensor is connected to a computer that is capable of fast Fourier (FFT) analysis. In both cases, by means of frequency response curves that are generated by FFT,

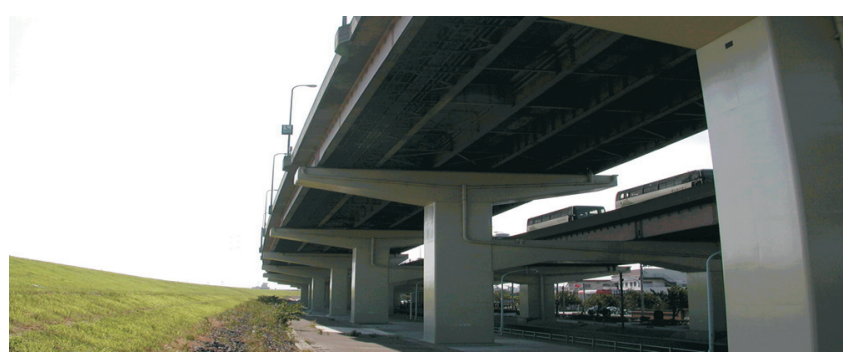

Figure 2. A real viaduct road model. 


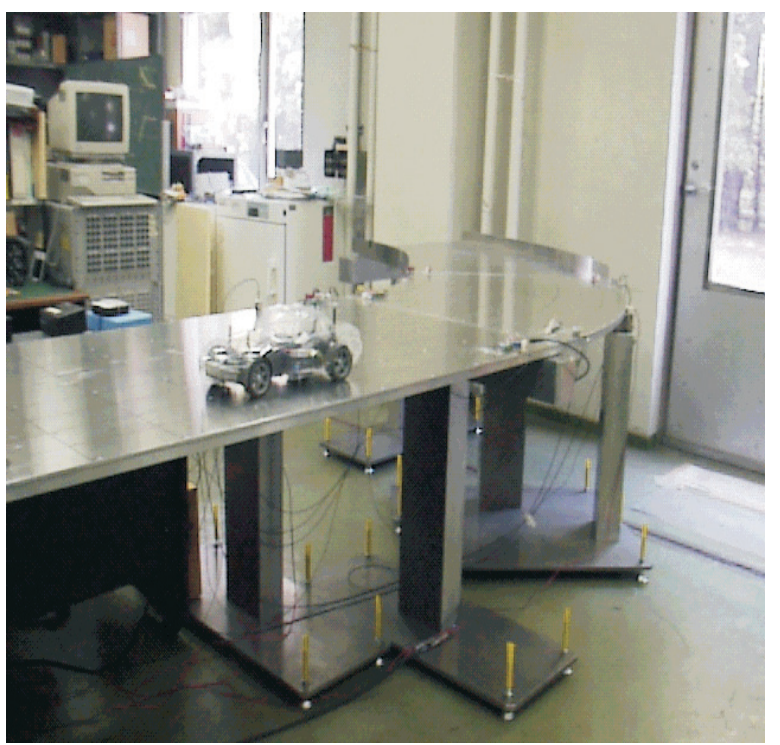

Figure 3. Experimental settings for viaduct road model.

critical frequencies are determined. Also synoise package program is used for finding mode shapes. Finally, it is observed that experimental mode shapes and the modes determined by finite element package program are the same.

\section{Neural networks (NN)}

Neural networks have been successfully used in many areas such as control and early detection of machine faults. The feed-forward neural network is usually trained by a back-propagation

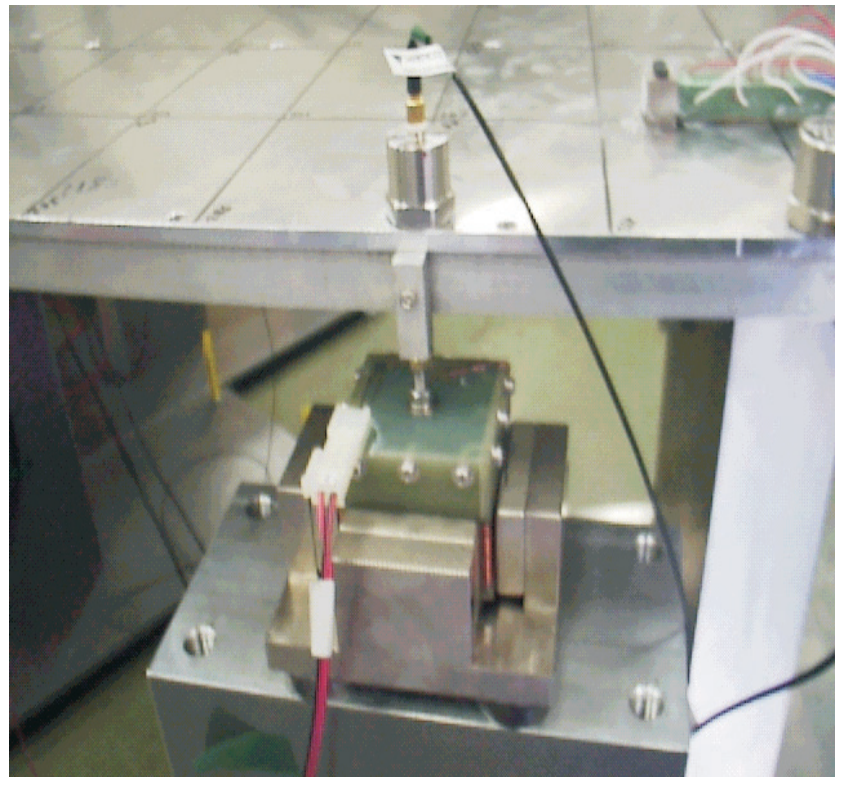

Figure 4. The sensor and magnetic force actuator. 
training algorithm first proposed by Rumelhart et al (1986). This was the effective usage of it only after 1980s. With the advantage of high speed computational technology, NNs are more realistic, easily updateable and implementable today. The distributed weights in the network contribute to the distributed intelligence or associative memory property of the network. With the network initially untrained, i.e., with the weights selected at random, the output signal patterns totally mismatch the desired output patterns for a given input pattern. The actual output pattern is compared with the desired output pattern and the weights are adjusted by the supervised back-propagation training algorithm until the pattern matching occurs, i.e., the pattern errors become acceptably small.

The impressive advantages of NNs are the capability of solving highly nonlinear and complex problems and the efficiency of processing imprecise and noisy data. In the following sections the Classic and the Fast Back-propagation NN algorithms are summarized.

\subsection{Classic back-propagation algorithm (CBA)}

Following equations show the basic steps of classic error back-propagation algorithm (Haykin 1999):

$$
\begin{aligned}
\text { if } o_{j} & =f\left(\text { net }_{j}\right)=f(x), \text { net }_{j}=\sum_{j}^{i} w_{j i} o_{i}+\theta_{j}, \\
E_{p} & =\frac{1}{2} \sum_{j-\text { output }}\left(t_{p j}-o_{p j}\right)^{2}, \\
\delta_{p j} & =\left(t_{p j}-o_{p j}\right) \\
\Delta_{p} w_{j i} & =-\alpha\left(\frac{\partial E_{p}}{\partial w_{j i}}\right) \\
\Delta_{p} \theta_{j} & =-\alpha\left(\frac{\partial E_{p}}{\partial \theta_{j}}\right) .
\end{aligned}
$$

In the operation element, if, as transfer (threshold) function we use "sigmoid" one,

$$
\begin{aligned}
o_{p j} & =\frac{1}{\sum_{i} 1+e^{-w_{j i} o_{p i}+\theta_{j}},} \\
\left(\text { net } p_{j}\right) & =\sum_{i} w_{j i} o_{p i}+\theta_{j} .
\end{aligned}
$$

Equation (14) is derived and simplied;

$$
\frac{\partial o_{p j}}{\partial \operatorname{net}_{p j}}=o_{p j}\left(1-o_{p j}\right) .
$$

Substituting in (14), for output element,

$$
\delta_{p j}=o_{p j}\left(t_{p j}-o_{p j}\right)\left(1-o_{p j}\right) .
$$

For hidden layer element,

$$
\delta_{p j}=o_{p j}\left(1-o_{p j}\right) \sum_{k} \delta_{p k} w_{k j} .
$$


If momentum term $(\varepsilon)$ is added to the general equation set to speed up the computation of the algorithm, in the most general condition, we get output and hidden layer equations as follows:

$$
\begin{aligned}
\Delta_{p} w_{j i}(t+1) & =\alpha \delta_{p j} o_{p i}+\varepsilon \Delta_{p} w_{j i}(t), \\
\Delta_{p} \theta_{j}(t+1) & =\alpha \delta_{p j}+\varepsilon \Delta_{p} \theta_{j}(t) .
\end{aligned}
$$

Here, $t$ is the number of learning cycles, $(\alpha)$ learning rate, $0 \cdot 01<\alpha<10,(\varepsilon)$ momentum rate, $0<\varepsilon<1$.

\subsection{Fast back-propagation algorithm (FBA)}

The fast version of the back-propagation algorithm (Karayiannis \& Venetsanopoulas 1991, $1992,1993)$ is derived by sequentially minimizing the objective function $G_{k}(\lambda)$, defined by (19), for $k=1,2, \ldots m$. The update equation for the synaptic weights $w_{p q}$ is obtained as (20).

$$
\begin{aligned}
& G_{k}\left(\lambda \lambda=\lambda \sum_{i=1}^{n_{0}} \phi_{2}\left(e_{i, k}\right)+(1-\lambda) \sum_{i=1}^{n_{0}} \phi_{1}\left(e_{i, k}\right) \forall k=1,2, \ldots, m,\right. \\
& w_{p, k}=w_{p, k-1}+\alpha \varepsilon_{p, k}^{0}(\lambda) \hat{h}_{k} .
\end{aligned}
$$

If the output of the network is analog,

$$
\varepsilon_{p, k}^{0}\left(\lambda \lambda=\lambda\left(y_{p, k}-\hat{y}_{p, k}\right)+(1-\lambda) \tanh \left[\beta\left(y_{p, k}-\hat{y}_{p, k}\right)\right] .\right.
$$

On the other hand, if the network has binary outputs,

$$
\varepsilon_{p, k}^{0}(\lambda)=\left(1-\hat{y}_{p, k}^{2}\right)\left(y_{p, k}-\lambda \hat{y}_{p, k}^{2}\right) .
$$

Because of its simplicity and fast nature, this algorithm provides an ideal basis for investigating the role of $\lambda$ during training. Here, $\varepsilon_{p, k}$ and $\alpha$ denote the output error and the learning rate, respectively. $\lambda$ is given as,

$$
\lambda=\exp \left(-\mu / E^{2}\right),
$$

where $\mu$ is controlled intuitively by the user with respect to the problem.

\section{Results}

After performing the simulation by using the above formulas, the system's natural frequency values are given for comparison in table 1 . In this study, frequency values of under $200 \mathrm{~Hz}$ are calculated. The experimental results by Nastran FEM analysis program are shown separately in this table. It can be seen that for low frequencies, critical frequency values of three different methods are very close to each other.

In neural networks application, for training purpose, 11 frequency values are taken as basis and other 5 natural frequencies are determined in test phase of the algorithm shown in table 2 . These determined values are very close to real ones. Thus, in this study, neural network method gives the designer not only an easy way to determine natural frequencies of the viaduct in order to detect the effects of vibration and noise, but also adaptive, practical and dynamic approach according to the other methods - Energy Method and FEM. In addition to this, 
Table 1. Natural frequency of viaduct road model under $200 \mathrm{~Hz}$.

\begin{tabular}{lcccc}
\hline $\begin{array}{l}\text { Mod } \\
\text { number }\end{array}$ & Mode & $\begin{array}{c}\text { Experimental } \\
\text { results (Hz) }\end{array}$ & $\begin{array}{c}\text { Energy } \\
\text { method (Hz) }\end{array}$ & FEM (Hz) \\
\hline 1 & $(1,1)$ & $10 \cdot 25$ & $10 \cdot 10$ & $10 \cdot 21$ \\
2 & $(2,1)$ & $16 \cdot 00$ & $15 \cdot 73$ & $15 \cdot 64$ \\
3 & $(1,2)$ & $40 \cdot 50$ & $40 \cdot 43$ & $39 \cdot 15$ \\
4 & $(3,1)$ & $48 \cdot 00$ & $43 \cdot 90$ & $44 \cdot 29$ \\
5 & $(2,2)$ & $49 \cdot 50$ & $50 \cdot 66$ & $47 \cdot 56$ \\
6 & $(3,2)$ & $74 \cdot 75$ & $75 \cdot 96$ & $73 \cdot 12$ \\
7 & $(1,3)$ & $86 \cdot 50$ & $90 \cdot 98$ & $85 \cdot 27$ \\
8 & $(2,3)$ & $94 \cdot 50$ & $108 \cdot 11$ & $93 \cdot 27$ \\
9 & $(4,1)$ & $112 \cdot 80$ & $103 \cdot 99$ & $105 \cdot 00$ \\
10 & $(3,3)$ & $122 \cdot 30$ & $135 \cdot 15$ & $123 \cdot 05$ \\
11 & $(4,2)$ & $135 \cdot 3$ & $129 \cdot 89$ & $129 \cdot 79$ \\
12 & $(1,4)$ & $145 \cdot 3$ & $161 \cdot 75$ & $145 \cdot 32$ \\
13 & $(2,4)$ & $156 \cdot 00$ & $188 \cdot 41$ & $152 \cdot 70$ \\
14 & $(4,3)$ & $177 \cdot 00$ & $182 \cdot 84$ & $174 \cdot 87$ \\
15 & $(3,4)$ & $184 \cdot 50$ & $220 \cdot 33$ & $182 \cdot 62$ \\
16 & $(5,1)$ & $201 \cdot 02$ & $195 \cdot 34$ & $198 \cdot 78$ \\
\hline
\end{tabular}

dynamic structure of NNs ensures an important advantage. The advantage is that, when the experimental results (for a defined scale of mode shape) are obtained once, there is no need to make measurements for in-scale values again. The architecture basis of the neural network tool and the comparison analysis of the results for both CBA and FBA are given in figures 5, 6 and 7 respectively. The numerical results of energy method is compared with NN results in table 2. It is easily shown that NNs allow the possibility of obtaining the desired in-scale value with its dynamic and adaptive structure in test phase.

Table 2. Neural network results compared with energy method ones.

\begin{tabular}{|c|c|c|c|}
\hline $\begin{array}{l}\text { Mod } \\
\text { number }\end{array}$ & $\begin{array}{c}\text { Energy } \\
\text { method }(\mathrm{Hz})\end{array}$ & $\begin{array}{c}\text { Neural } \\
\text { network (CBA) } \\
\text { results (Hz) }\end{array}$ & $\begin{array}{c}\text { Neural } \\
\text { network }(\mathrm{FBA}) \\
\text { results }(\mathrm{Hz})\end{array}$ \\
\hline 1 & $10 \cdot 10$ & & \\
\hline 2 & $15 \cdot 73$ & & \\
\hline 3 & $40 \cdot 43$ & $38 \cdot 95$ & $41 \cdot 19$ \\
\hline 4 & 43.90 & & \\
\hline 5 & $50 \cdot 66$ & & \\
\hline 6 & 75.96 & & \\
\hline 7 & $90 \cdot 98$ & 89.87 & 89.91 \\
\hline 8 & $108 \cdot 11$ & & \\
\hline 9 & 103.99 & $103 \cdot 406$ & 103.447 \\
\hline 10 & $135 \cdot 15$ & & \\
\hline 11 & $129 \cdot 89$ & $131 \cdot 116$ & $128 \cdot 292$ \\
\hline 12 & 161.75 & & \\
\hline 13 & 188.41 & & \\
\hline 14 & $182 \cdot 84$ & $183 \cdot 18$ & 182.53 \\
\hline 15 & $220 \cdot 33$ & & \\
\hline 16 & $195 \cdot 34$ & & \\
\hline
\end{tabular}




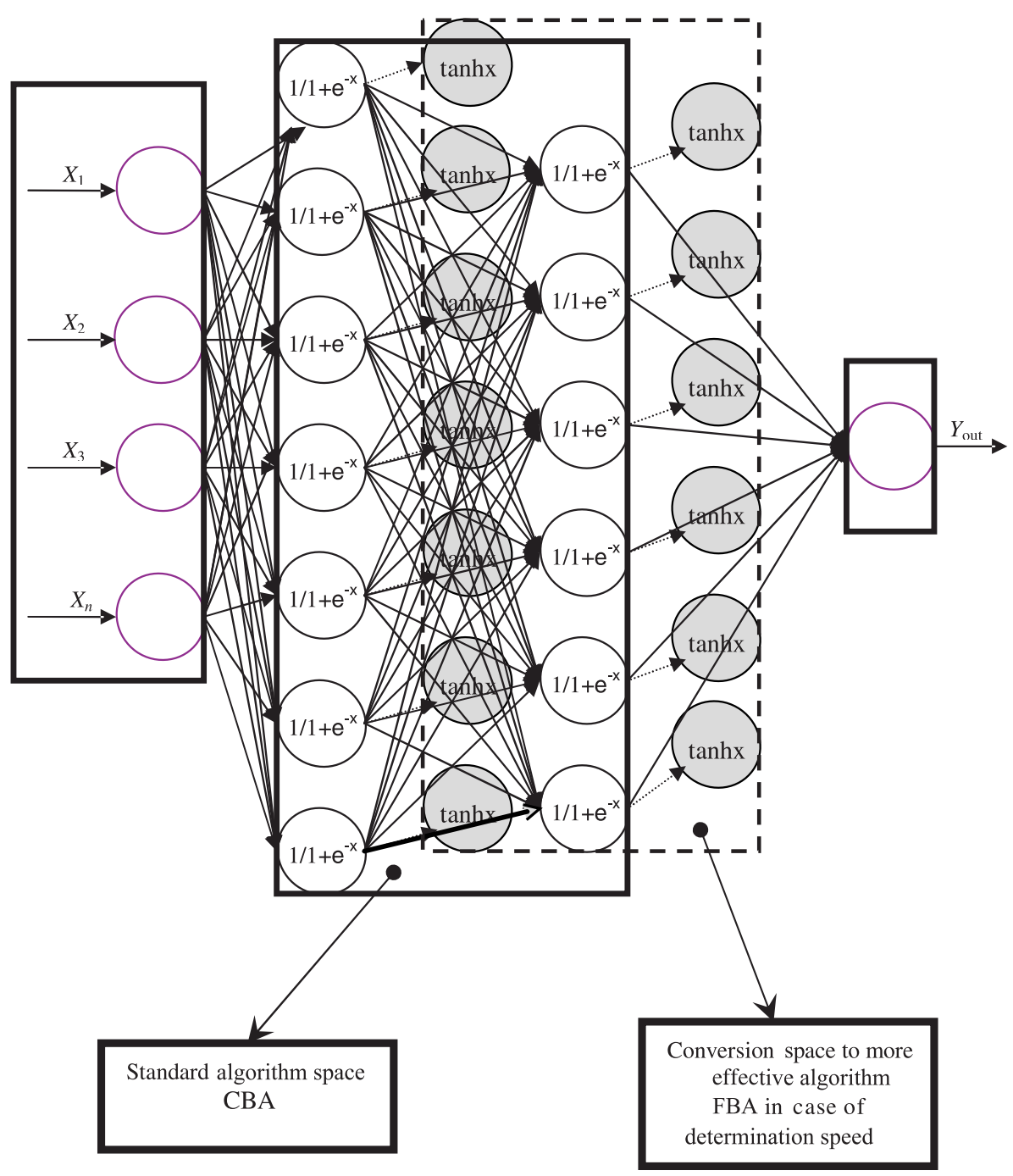

Figure 5. Neural network architecture of proposed system.

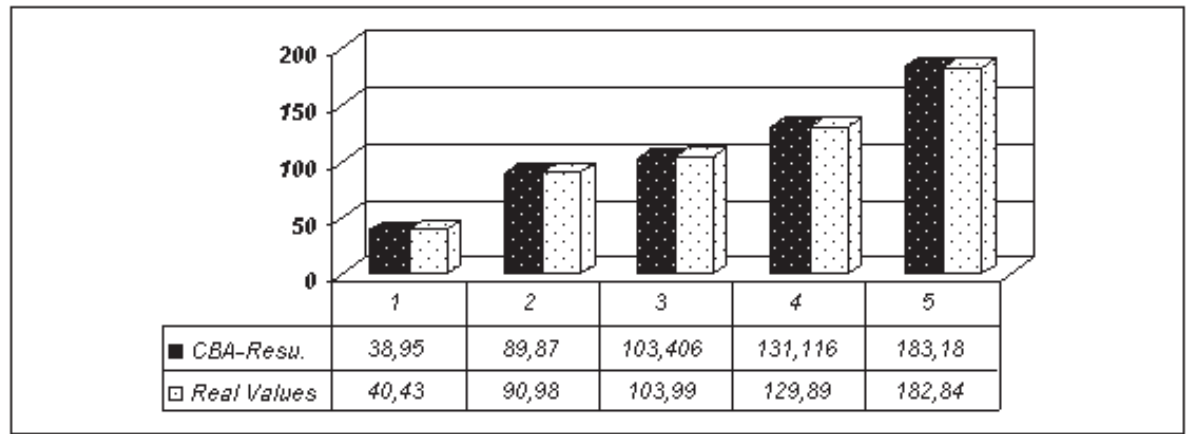

Figure 6. CBA results of energy method for 5 test values. 


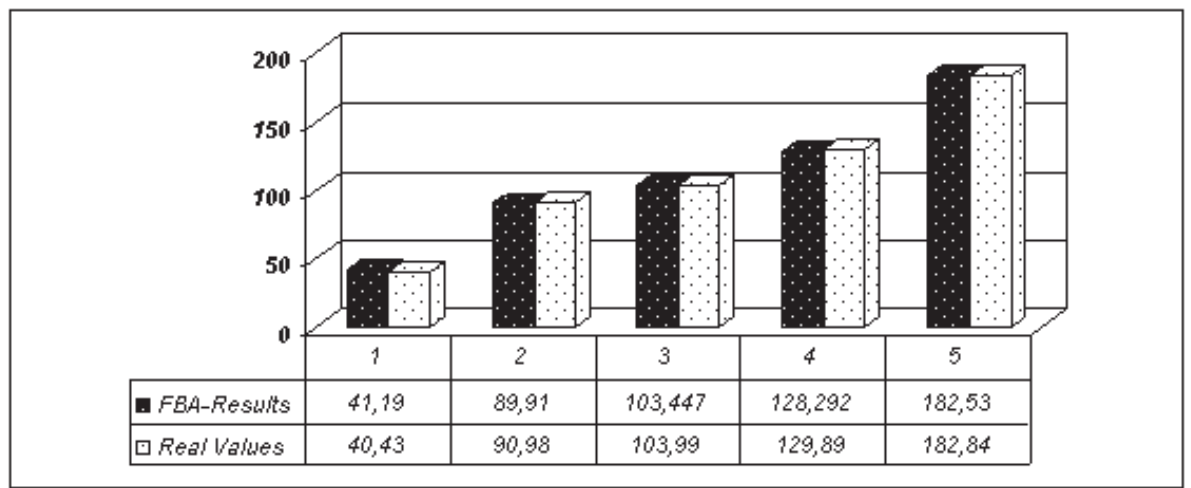

Figure 7. FBA results of energy method for 5 test values.

\section{Conclusions}

The first aim of this study is to obtain an artificial neural network based tool to suppress vibration and noise on highways, which has a wide application in big cities with high traffic loads in order to decrease the traffic density end to connect the subways to highways. The second one is to ensure a robust comparison between the methods of NNs, energy method and FEM. The proposed tool is able to predict the natural frequency values of the system with a high precision even with a few experimental values. The application range and reliability rate of the proposed model can be improved by deriving the $\mathrm{NN}$ dynamic structure enriched by additional or specific data. Furthermore, depending on the convenience of the design data structure, the proposed model can easily be generalized and reconstructed for other different mode applications of viaducts.

\section{List of symbols}

Viaduct properties

$a \quad$ side of the plate parallel to $x$ axis;

$a_{1}, a_{2}, \ldots \quad$ constant coefficients in displacement function $w$ for stiffened plates;

$A_{k} \quad$ lateral cross-section of beam;

$b \quad$ side of the plate parallel to $y$ axis;

$b_{1} \quad$ width of beam;

$D \quad$ bending rigidity of the plate;

E elastic modulus of plate;

$E_{k} \quad$ elastic modulus of beams;

$\phi_{m} \quad$ figure function for the free boundary conditioned beam;

$G_{k} \quad$ shear modulus of beams;

$H \quad$ height of plate;

$h_{1} \quad$ height of beams;

$I_{k} \quad$ moment of Inertia;

$I_{0} \quad$ polar moment of inertia of each beam;

$x_{k} \quad$ location of beams under plate; 


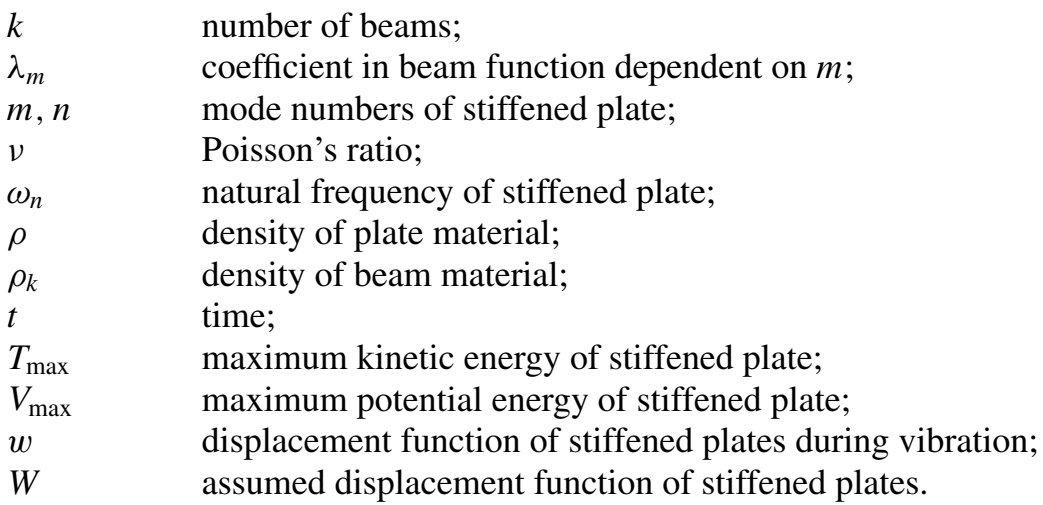

Neural networks

$\begin{array}{ll}G(\lambda) & \text { generalized objective function; } \\ i, j & \text { learning set matrix indices; } \\ t & \text { the number of learning cycles; } \\ w & \text { synaptic weights; } \\ \alpha & \text { learning rate; } \\ \varepsilon & \text { momentum coefficient; } \\ \lambda & \text { input variable; } \\ o & \text { output variable. }\end{array}$

\section{References}

Balendra T, Shanmugan N E 1982 Free vibration of plates structures by grillage method. J. Sound Vib. 99: 333-350

Bassily S F, Dickinson S M 1975 On the use of beam functions for problems of plates involving free edges. J. Appl. Mech. December: 858-864

Bert C W, Newberry A L 1986 Improved finite element analysis of beam vibration. J. Sound Vib. 105: 179-183

Bhat R B 1982 Vibrations of panels with non-uniformly spaced stiffners. J. Sound Vib. 84: 449-452

Haykin S 1999 Neural networks (MacMillan)

Heyliger P R, Reddy J N 1988 A higher order beam finite element for bending and vibration problems. J. Sound Vib. 126: 309-326

Karayiannis N B, Venetsanopoulas A N 1991 Fast learning algorithms for neural networks in artificial neural networks: Proc. 1991 Int. Conf. on Artificial Neural Networks (ICANN-91) Espoo (Helsinki: Elsevier) pp. 1141-1144

Karayiannis N B, Venetsanopoulas A N 1992 Fast learning algorithms for neural networks. IEEE Trans. Circuits Syst.-II 39(7): 453-474

Karayiannis N B, Venetsanopoulas A N 1993 Artificial neural networks - learning algorithms, performance evaluation and applications (Kluwer Academic)

Kim C S, Dickinson S M 1987 The Flexural vibration of line supported rectangular plate systems. J. Sound Vib. 114: 129-142

Kim C S, Young P G, Dickinson S M 1990 On the flexural vibration of rectangular plates approached by using simple polynomials in the Rayleigh-Ritz method. J. Sound Vib. 143: 379-394

Leissa A W 1969 Vibration of plates, NASA SP-160 
Leissa A W 1973 The free vibration of rectangular plates. J. Sound Vib. 31: 257-293

Long B R 1971 A stiffness-type analysis of the vibration of a class of stiffened plates. J. Sound Vib. 16: $323-335$

Mukherjee A, Mukhopadhyay M 1988 Finite element free vibration of eccentrically stiffened plates. Comput. Struct. 30: 1303-1317

Mukhopadhyay M 1989 Vibration and stability analysis of stiffened plates by semi-analytic finite difference method, Part II: Consideration of bending and axial displacement. J. Sound Vib. 130: $41-53$

Ney S F, Kulkarni G G 1972 On the transverse free vibration of beam-slab type highway bridges. J. Sound Vib. 21: 249-261

Rumelhart E, Hinton G E, Williams R J 1986 Learning representation by back-propagation errors. Nature (London) 323: 533-536

Sakata T, Hosokawa K 1988 Vibrations of clamped orthotropic rectangular plates. J. Sound Vib. 125: 429-439

Srinivasan R S, Munaswamy K 1978 Dynamic response analysis of stiffned slab bridges. Comput. Struct. 9: 559-566

Szilard R 1974 Theory and analysis of plates (Englewood Cliffs, NJ: Prentice-Hall)

Rao S S 1995 Mechanical vibrations 3rd edn (New York: Addison Wesley)

Young D 1950 Vibration of rectangular plates by the Ritz method. J. Appl. Meth. 17: 448-453

Yuksek I, Kikushima Y, Sivrioglu S, Tanaka N 2000 Cluster control of a viaduct road. Proc. JSME Annual Meeting, Nagoya, Japan 